\title{
Determination of 7 Indictor Polychlorinated Biphenyls (PCBs) Residues in Porphyra by Ultrasonic Extraction and Gas Chromatography (GC)
}

\author{
Liangliang Tian', Feng Han'1, Youqiong Cai ${ }^{1}$, Cong Kong1, Yongfu Shi' ${ }^{1}$, Yuan Wang1, \\ Guangxin Yang1, Qianyun Zhan ${ }^{1,2}$, Dongmei Huang ${ }^{*}$ \\ ${ }^{1}$ Aquatic Product Quality Inspection and Test Center (Shanghai), Ministry of Agriculture of China, East China \\ Sea Fisheries Research Institute, Shanghai, China \\ ${ }^{2}$ College of Food Science and Engineering, Ocean University of China, Qingdao, China \\ Email: liangliangjia@126.com, "hdm2001@126.com
}

Received 7 March 2016; accepted 31 March 2016; published 7 April 2016

\section{Abstract}

A method was developed for determination of 7 indictors the polychlorinated biphenyls (PCBs) residues in porphyra by gas chromatography (GC) with electron capture detector (ECD). The PCBs were extracted with hexane/methylene chloride $(1: 1, v / v)$ by ultrasonic extraction and the samples were cleaned up by concentrated sulfuric acid and Alumina- $\mathrm{N}$ solid phase extraction cartridge. The analytes were quantified by an internal standard method. Under optimal experimental conditions, good linearity was observed in the range of $5-200 \mathrm{ng} / \mathrm{mL}$ and the correlation coefficients were $0.9994-0.9998$. The limit of quantitation (LOQ) for target analytes ranged from 6.0 to 10.0 $\mu \mathrm{g} / \mathrm{kg}$. At the spiked levels of $10,50,100 \mu \mathrm{g} / \mathrm{kg}$, the average recoveries ranged from $90.9 \%$ to $102 \%$ with the relative standard deviations $2.12 \%-6.32 \%$. The result showed that the proposed method was rapid, and could be used for the determination of the PCBs in porphyra.

\section{Keywords}

Polychlorinated Biphenyls (PCBs), Porphyra, Ultrasonic Extraction, Gas Chromatography (GC)

\section{Introduction}

The PCBs (Polychlorinated biphenyls) which were widely used in industry from 1929 to 1979 in world have caused global environmental pollution problems because of their their persistence and multiple dimensions of toxicity. Many offshore waters have been contaminated by the PCBs in our country, the concentration is more than $30 \mathrm{ng} / \mathrm{L}$ standards that was promulgated by the US EPA [1]. The PCBs may damage the immune system, reproductive system, nervous system with bioaccumulation and carcinogenicity in human body, and that were

${ }^{*}$ Corresponding author.

How to cite this paper: Tian, L.L., et al. (2016) Determination of 7 Indictor Polychlorinated Biphenyls (PCBs) Residues in Porphyra by Ultrasonic Extraction and Gas Chromatography (GC). Journal of Agricultural Chemistry and Environment, 5, 1-5. http://dx.doi.org/10.4236/jacen.2016.51B001 
listed to be one of the 12 kinds of persistent organic pollutants to priority control in the Stockholm convention.

Porphyra contains rich vitamin, iodine, protein, inorganic salt, etc and can make food after drying. China accounts for the world first in porphyra output [2]. Porphyrais one of the main economic seaweed in our country. Porphyralives in the high-water line of the shallow intertidal zone and grows best in the nitrogen-rich water (such as the sewage outfall), so it is easy to enrich organic pollutants and contaminated by the PCBs. In order to monitor the safe state of the porphyra, there is a need to establish a detection method.

Accurate quantification of PCBs requires efficient extraction and detection methods to minimize the interferences contributed by the matrix. The detection methods are mainly gas chromatography (GC) and gas chromatography mass spectrometry (GC/MS). The PCB recovery has been performed by soxhlet extract [3], sonication techniques [4] and other newer techniques such as microwave extraction [5], supercritical fluid extraction [6], and accelerated solvent extraction(ASE) [7], which are time-consuming or require the corresponding instrument, and the sample types are shellfishes, seaweed, blue crab, treebark, fish,etc.. The porphyra contains chlorophyll, carotenoids, lutein, phycoerythrin, blue protein, etc. and almost no fat, that matrix is very different with any other organisms. Accordingly, it is needed to establish a method to detect the PCBs in the porphyra because there is no an effective method suitable for porphyra. So this paper describes a quick, effective, simple and accurate method to monitor the PCBs that the extraction method is soaking-ultrasonic and the detection is method GC.

\section{Materials and Method}

\subsection{Materials and Instrument}

HPLC grade solvents purchased from Mallinckrodt Baker, Inc were used in this study.PCB contaminants were purchased from Dr. Ehrenstorfer Company. Porphyra samplings were purchased from supermarket. Neutral alumina solid phase extraction cartridge (Alumina-N SPE, $500 \mathrm{mg} / 6 \mathrm{~mL}$ ) were purchased from Agela Company.

The GC system consisted of an Agilent 7890A GC (Agilent Technologies, Shanghai, China), equipped with an electron capture detector (ECD). The GC was fitted with a J \& W DB-5MS fused silica capillary column (5\% phenyl polysiloxaneas non-polar stationary phase, $30 \mathrm{~m}, 0.25 \mathrm{~mm}$ i.d. and $0.25 \mathrm{~lm}$ film thickness) from Agilent (J\&W Scientific, Folson, CA, USA). Nitrogen with a purity of $99.999 \%$ was used as the carrier gas.

Stock solutions were prepared for all standard substances at $1.0 \mu \mathrm{g} / \mathrm{mL}$ in n-hexane. Spiking and calibration mixtures at various concentration levels were obtained by combing aliquots of stock solutions and internal standard with n-hexane and stored at $-20^{\circ} \mathrm{C}$. The concentration of internal standard in all the calibration mixtures and final sample solutions was $40 \mathrm{ng} / \mathrm{mL}$.

\subsection{Method}

About 2.5 g of porphyra sample were weighed in a $50 \mathrm{~mL}$ centrifuge tube and spiked with 40 ng PCB 198 as the internal standard. The extraction was made with two $25 \mathrm{ml}$ aliquots of a mixture of n-hexane/dichloromethane (1:1 v:v) [8] for $2 \mathrm{~h}$ of soaking and $20 \mathrm{~min}$ of ultrasonic. Then each mixture was centrifuged at $8000 \mathrm{r} / \mathrm{min} \mathrm{g}$ for $8 \mathrm{~min}$. The two extracts were joined together and evaporated in a rotary evaporator to dry at a low temperature and weak vacuum. The residue was dissolved by $8 \mathrm{ml}$-hexane twice and then the dissolved solution was subjected to cleanup.

The dissolved solution was added $3 \mathrm{~mL}$ concentrated sulfuric acid and fully shocked for 2 min, Then the mixture was centrifuged at $2000 \mathrm{r} / \mathrm{min}$ g for $5 \mathrm{~min}$. The supernatant was normally passed through an AluminaNSPE cartridge conditioning with $5 \mathrm{ml}$-hexane without any pressure. The eluate was collected and another 3 $\mathrm{ml} n$-hexane was used to rinse the analytes. The eluate was dried under a gentle nitrogen stream at $40^{\circ} \mathrm{C}$. The residue was reconstituted with $1 \mathrm{~mL}$-hexane and mixed in a vortex stirrer.

\subsection{GC Analysis}

The final samples were detected on an Agilent 7890A GC, coupled to an electron capture detector (ECD). The column temperature program was as below: $150^{\circ} \mathrm{C}$ hold for $0 \mathrm{~min}$, ramp at $15^{\circ} \mathrm{C} \mathrm{min}{ }^{-1}$ to $200^{\circ} \mathrm{C}$, hold for 0 min, ramp at $2^{\circ} \mathrm{C} \mathrm{min}{ }^{-1}$ to $270^{\circ} \mathrm{C}$, hold for $2 \mathrm{~min}$, ramp at $10^{\circ} \mathrm{C} \min ^{-1}$ to $280^{\circ} \mathrm{C}$, and hold for 1 min. The carrier gas

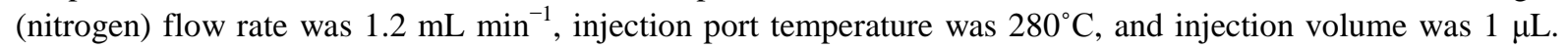
The injection was made in the splitless mode with purge on after $0.75 \mathrm{~min}$. 


\section{Results and Discussion}

\subsection{Extraction Method}

The extraction methods of the PCBs widely used are Soxhlet extraction, accelerated solvent extraction (ASE) and the ultrasonic extraction at present. Soxhlet extraction time is so long that needs $24 \mathrm{~h}$. ASE that runs at high temperature and high pressure conditions requires specialized equipment and cost high. Ultrasonic extraction can shorten the extraction time relative to the Soxhlet extraction and has no special requirements for conditions of use relative to the ASE, so that meets the requirements of improving the efficiency of extracting and easy to use. In this study, the result showed that the extracting effect of ultrasonic after soaking was better than ultrasonic without soaking. The recovery of the method of Soaking for $2 \mathrm{~h}$ and ultrasonic for $20 \mathrm{~min}$ could reach $90 \%$, so this extract method was used.

\subsection{Optimization of Sample Purification}

In order to determine the trace level of the PCBs, it is advantageous to eliminate any possible interference from samples. The composition of the impurities in Porphyrais very complex. There was some matrix to interfere the PCB 28 and PCB 153 to detect when only concentrated sulphuric acid was used to purify the sample, and it could not reduce interference by increasing the amount of sulfuric acid. With alumina-NSPE only, the solution after purification was not clear which proved that the impurities could not be completely removed. Combined with concentrated sulfuric acid and alumina-NSPE, the target analytes could be accurately analyzed. Figure 1 presented the chromatograms of 7 chemicals at $10 \mu \mathrm{g} / \mathrm{kg}$ of spiked level.

\subsection{Method Performance}

The calibration curves for detection of the target compounds were obtained by performing a linear regression analysis on standard solution using the ratio of standard area to internal standard area (PCB 198) against analyte concentrations ranging from 5 to $200 \mathrm{ng} / \mathrm{mL}$ containing $40 \mathrm{ng} / \mathrm{mL}$ internal standard. Good linearity was obtained for all analytes, with correlation coefficients of $\mathrm{R}^{2}$ ranged from 0.9994 to 0.9998 . The limit of detection (LOD), defined as the concentration which yield a signal-to-noise (S/N) equal to 3, ranged from $2 \mu \mathrm{g} / \mathrm{kg}$ to $4 \mu \mathrm{g} / \mathrm{kg}$ (Table 1), The limit of quantification(LOQ), defined as the concentration which yield an $\mathrm{S} / \mathrm{N}$ equal to 10 , ranged from $6 \mu \mathrm{g} / \mathrm{kg}$ to $10 \mu \mathrm{g} / \mathrm{kg}$ (Table 1). The analytes recovery of this procedure was evaluated by spiking 10, 50 and $100 \mu \mathrm{g} / \mathrm{kg}$ of each standard analyte and $40 \mathrm{ng}$ internal standard to sample at three levels in replicates of six. The results are listed in Table 2; the average recoveries of each compound ranged from $90.9 \%$ to $102 \%$. The reproducibility of this method was represented by percent relative standard deviation (R.S.D.) at each level for each compound and these values are also summarized in Table 2. The results show that the method's precision was within $10 \%$, which is very satisfactory.

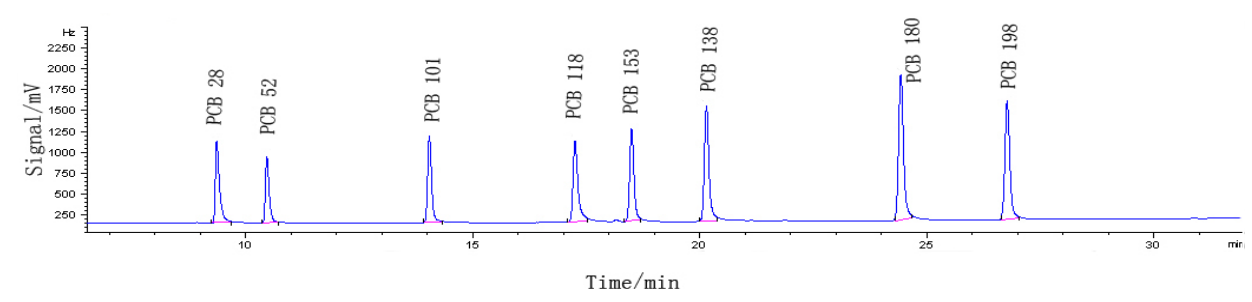

(a)

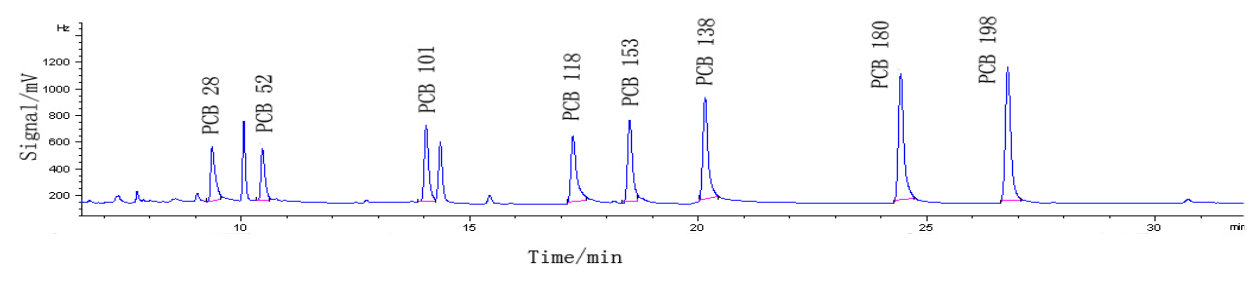

(b)

Figure 1. GC chromatograms of PCBs standard (a) and real sample (b). 
Table 1. Linearity, the limit of detection (LOD) and the limit of quantification(LOQ) for 7 indictor PCBs.

\begin{tabular}{ccccc}
\hline compounds & Calibration equation & $\mathrm{R} 2$ & $\mathrm{LOD}(\mu \mathrm{g} / \mathrm{kg})$ & $\mathrm{LOQ}(\mu \mathrm{g} / \mathrm{kg})$ \\
\hline PCB28 & $\mathrm{Y}=0.5226 \mathrm{X}-0.02819$ & 0.9994 & 4.0 & 10.0 \\
PCB52 & $\mathrm{Y}=0.3430 \mathrm{X}-0.00171$ & 0.9997 & 4.0 & 10.0 \\
PCB101 & $\mathrm{Y}=0.4976 \mathrm{X}-0.01042$ & 0.9997 & 3.0 & 9.0 \\
PCB118 & $\mathrm{Y}=0.6187 \mathrm{X}-0.02979$ & 0.9996 & 3.0 & 9.0 \\
PCB153 & $\mathrm{Y}=0.5947 \mathrm{X}-0.01647$ & 0.9997 & 3.0 & 9.0 \\
PCB138 & $\mathrm{Y}=0.8151 \mathrm{X}-0.03589$ & 0.9994 & 3.0 & 9.0 \\
PCB180 & $\mathrm{Y}=1.0978 \mathrm{X}-0.04450$ & 0.9998 & 2.0 & 6.0
\end{tabular}

Table 2. Recoveries and R.S.D. of spiked porphyra $(n=6)$.

\begin{tabular}{ccccccc}
\hline \multirow{2}{*}{ compounds } & \multicolumn{2}{c}{ Spiked level $(10 \mu \mathrm{g} / \mathrm{kg})$} & \multicolumn{2}{c}{ Spiked level $(50 \mu \mathrm{g} / \mathrm{kg})$} & \multicolumn{2}{c}{ Spiked level $(100 \mu \mathrm{g} / \mathrm{kg})$} \\
\cline { 2 - 7 } & Recovery (\%) & R.S.D. (\%) & Recovery (\%) & R.S.D. (\%) & Recovery (\%) & R.S.D. (\%) \\
\hline PCB 28 & 95.2 & 4.21 & 101 & 3.78 & 93.2 & 3.26 \\
PCB 52 & 92.8 & 3.58 & 92.8 & 3.97 & 98.3 & 2.68 \\
PCB 101 & 96.5 & 5.06 & 95.2 & 4.66 & 95.1 & 4.01 \\
PCB 118 & 98.1 & 4.32 & 98.4 & 6.32 & 90.9 & 3.82 \\
PCB 153 & 94.6 & 3.77 & 97.8 & 4.21 & 102 & 3.21 \\
PCB 138 & 93.4 & 2.58 & 96.2 & 3.35 & 99.3 & 2.12 \\
PCB 180 & 98.9 & 3.05 & 96.6 & 3.12 & 98.5 & 2.44 \\
\hline
\end{tabular}

\section{Conclusion}

In this investigation, a comprehensive analytical method was developed for simultaneous extraction and determination of seven indicator PCBs in porphyra. The method clearly demonstrated good linearity, accuracy, and precision. Good recoveries ranging from $90.9 \%$ to $102 \%$ were reached. This new method may be suitable for the surveillance of the PCBs compounds in porphyra contaminated by the sea environment.

\section{Acknowledgements}

The authors would like to thank the financial support of the project (No. 2014T14) by special research fund for the national non-profit institutes (East China Sea Fisheries Research Institute).

\section{References}

[1] Liu, M.X., Yang, Y.Y., Li, Q.X. and Wang, J. (2013) Status and Influencing Factors of Polychlorinated Biphenyls (PCBs) Pollution in the Coastal Areas in China. Environmental Science, 34, 3309-3314.

[2] Li, X.C. (2011) Industry Development, Standard and Safety Assessment of Seaweed in China. Chinese Fishery Quality and Standards, 1, 9-12.

[3] Fang, J. and Wang, K.X. (2007) Multiresidual Analysis of Organochlorine Pesticides, Polychlorinated Biphenyls and Polycyclic Aromatic Hydrocarbons in Marine Shellfishes by Gas Chromatography-Ion Trap Mass Spectrometry. Chinese Journal of Analytical Chemistry, 35, 1607-1613. http://dx.doi.org/10.1016/S1872-2040(07)60095-4

[4] Pavoni, B., Caliceti, M., Sperni, L. and Sfriso, A. (2003) Organic Micropollutants (PAHs, PCBs, Pesticides) in Seaweeds of the Lagoon of Venice. Oceanologica Acta, 26, 585-596. http://dx.doi.org/10.1016/s0399-1784(03)00052-5

[5] Bruzzonitia, M.C., Mainab, R., Tumiattib, V., Sarzaninia, C., Rivoiraa, L. and De Carloa, R.M. (2012) Fast LowPressure Microwave Assisted Extraction and Gas Chromatographic Determination of Polychlorinated Biphenyls in Soil Samples. Journal of Chromatography A, 1265, 31-38. http://dx.doi.org/10.1016/j.chroma.2012.09.089 
[6] Gaylor, M.O. and Hale, R.C. (2015) Systematic Investigation of Factors Controlling Supercritical Fluid Extraction (SFE) of Spiked and Aged PCBs from EdibleTissues of the Blue Crab (Callinectes sapidus). Bulletin of Environmental Contamination and Toxicology, 94, 23-28. http://dx.doi.org/10.1007/s00128-014-1380-9

[7] Guéguen, F., Stille, P. and Millet, M. (2013) Optimisation and Application of Accelerated Solvent Extraction and Flash Chromatography for Quantification of PCBs in Tree Barks and XAD-2 Passive Samplers Using GC-ECD with Dual Columns. Talanta, 111, 140-146. http://dx.doi.org/10.1016/j.talanta.2013.02.056

[8] Tian, L.L., Shi, Y.F., Wang, Y., Cai, Y.Q., Yu, H.J., Qian, B.L. and Huang, D.M. (2014) Determination of Organochlorine Pesticide and Polychlorinated Biphenyl Residues in Shrimp by Gas Chromatography. Chinese Journal of Analysis Laboratory, 33, 1043-1046. 